\title{
CIHR doubles support for clinical research
}

$\mathrm{T}$ he Canadian government will double its funding of clinical research over the next five years as part of a renewed partnership with drug companies, Minister of Health Leona Aglukkaq announced Mar. 22.

The Canadian Institutes of Health Research (CIHR) will invest up to $\$ 150$ million in a collaborative research program with Canada's ResearchBased Pharmaceutical Companies $(\mathrm{Rx} \& \mathrm{D})$ to fund and improve the coordination of clinical research across the country, Aglukkaq told reporters at a press conference in Ottawa, Ontario.

One of the main goals of CIHR's renewed partnership with $\mathrm{Rx} \& \mathrm{D}$ will be "increasing the number of innovative health treatments and devices ... that make it to the market," she said.

The new funding will also support implementation of CIHR's Strategy for Patient-Oriented Research to ensure better translation of research findings into clinical practice by developing and implementing tools to support, train, recruit and retain researchers such as clinical investigators, biostatisticians, methodologists, epidemiologists, health economists and technicians (www.cihr -irsc.gc.ca/e/documents/P-O_Research _Strategy-eng.pdf).

"We are certain that greater collaboration will open up more pathways to transform research concepts into actual practices of medicine ... [and] ensure the right patient receives the right medical care at the right time," Aglukkaq said.

Launched last year, the strategy is aimed at closing gaps in Canada's research-to-practice continuum, including:

- "Lack of clinical investigators, methodologists such as biostatisticians, clinical epidemiologists and health economists, and other needed experts;

- Complicated coordination of large, multi-centre clinical trials because of requirements for multiple ethics

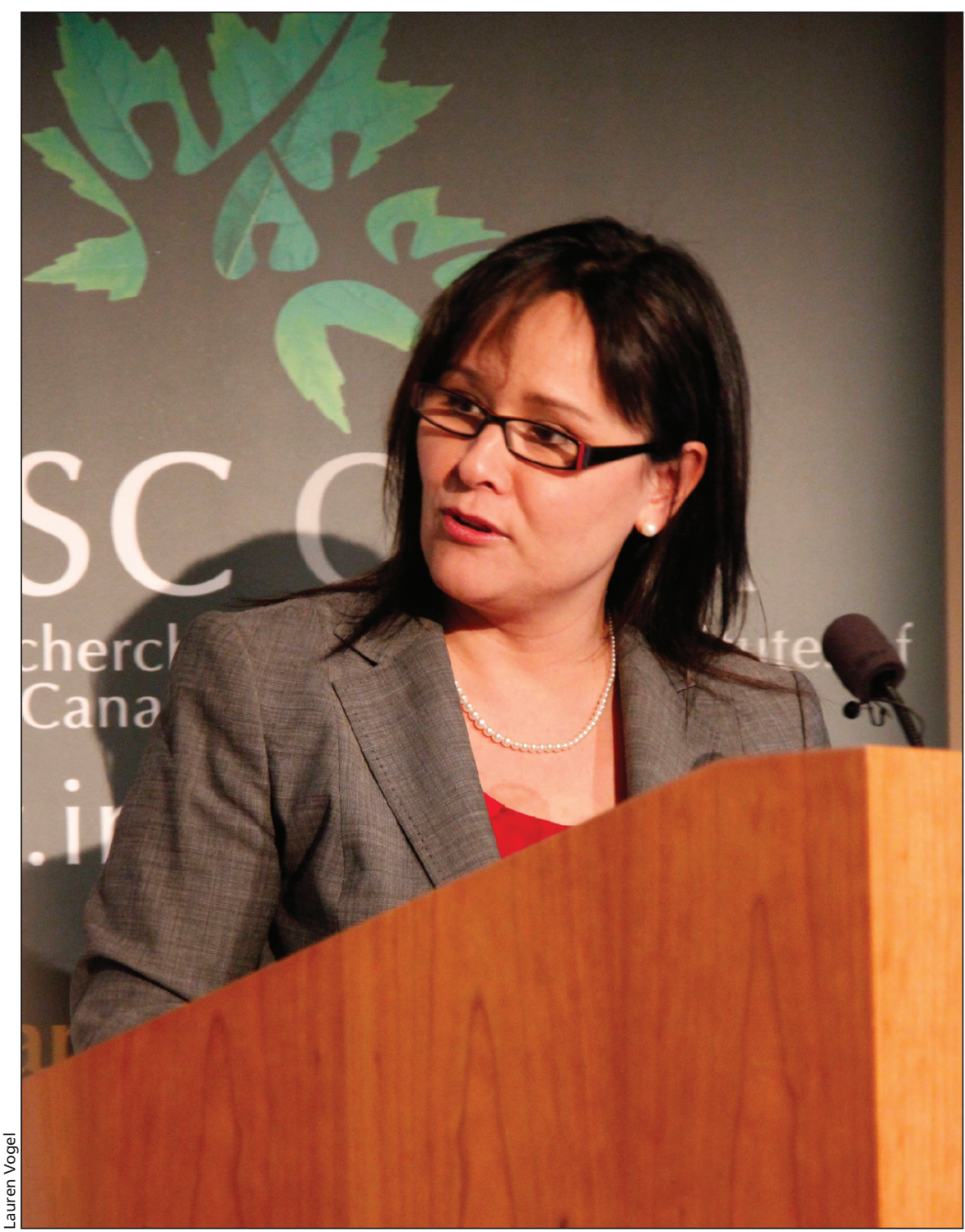

Federal Health Minister Leona Aglukkaq says the government's partnership with drug companies will increase the number of "innovative health treatments and devices" that make it to market.

reviews by each individual institution and the lack of standardized contracts;

- Underfunding of patient-oriented research when compared to many other countries;

- A decentralized federation structure, making research coordination difficult;

- Deficiencies in the development and dissemination of guidelines and their adoption into practice, despite their proven value; and

- The limited role of patients in patientoriented research," according to a background statement on the strategy (www.cihr-irsc.gc.ca/e/43999.html).

Closing such gaps would be a "strong step forward" to Canada securing "a greater share of the almost $\$ 100$ billion that our industry invests in research around the world," Rx\&D 
President Russell Williams said at the press conference.

According to Williams, Rx\&D member companies have set an objective to match CIHR investments to clinical research "dollar-for-dollar."

The pharmaceutical industry has also partnered with the federal government to accelerate reviews of alternatives to drugs currently in severe shortage across the country.

"In normal circumstances a review would take up to 6 months. In this situation, we're looking at getting through the process in one month," Aglukkaq said.

Moreover, the federal government has ramped up development of a "one- stop shop" reporting system for current and impending drug shortages that's been in the offing for over a year.

Currently, health practitioners can access national data on shortages flagged by generic and brand-name drug-makers at two websites that previously reported strictly on regional supply disruptions: the Saskatchewan Drug Information Service (http://druginfo .usask.ca/healthcare_professional/drug _shortages.php) and Vendredi PM (http://vendredipm.wordpress.com). But the makeshift registries are just a "temporary step" toward a truly comprehensive drug shortage monitoring system, as they only capture supply problems flagged by industry and don't provide information about therapeutic alternatives (www.cmaj.ca/lookup/doi/10.1503 /cmaj.109-4100).

Although it's impossible to "do away with drug shortages" completely, establishing a centralized reporting system "will allow provinces and territories and hospitals to plan ahead," Aglukkaq said. "Whether you're triaging or looking at alternate products ... it would allow us the time to respond to ensure that patients who need [drugs in short supply] continue to receive that care." — Lauren Vogel, CMAJ

CMAJ 2012. DOI:10.1503/cmaj.109-4161 